\title{
Interview Records of Prof. Liu Chunjiang, Qingyang Opera Researcher and Expert
}

\author{
Jiaqi Mei \\ School of Art, Jiujiang University, Jiujiang City, Jiangxi Province, China \\ audiomjq@qq.com
}

Key word: Qingyang Opera; Liu Chunjiang; Interview Records

\begin{abstract}
Qingyang Opera, title of Huizhou Opera and Qingyang Opera, is a rare art in the field of Chinese opera. However, the ancient art has been at the risk of disappearing. Since 1980, Prof. Liu Chunjiang has been studying Qingyang Opera for about 30 years, this author interviewed Prof. Liu Chunjiang and strived to collect data concerned, with the first hand data held, it is expected to make a few contributions to the protection of Qingyang Opera-a state-level intangible cultural heritage.
\end{abstract}

\section{青阳腔戏曲研究专家刘春江教授访问记录}

梅佳琪

九江学院艺术学院, 九江, 江西, 中国

audiomjq@qq.com

\section{关键词：青阳腔 刘春江 口述史}

摘要. 青阳腔被誉为中国戏曲艺术的奇珍, 素有 “徽池雅调” 之称。但这一古老的戏曲艺术 濒临绝响。刘春江教授自 1980 年开始研究青阳腔, 至今 30 余年。通过现场采访刘春江教 授, 强化资料收集工作, 以鲜活的第一手资料, 为保护国家级非物质文化遗产——青阳腔, 尽绵薄之力。

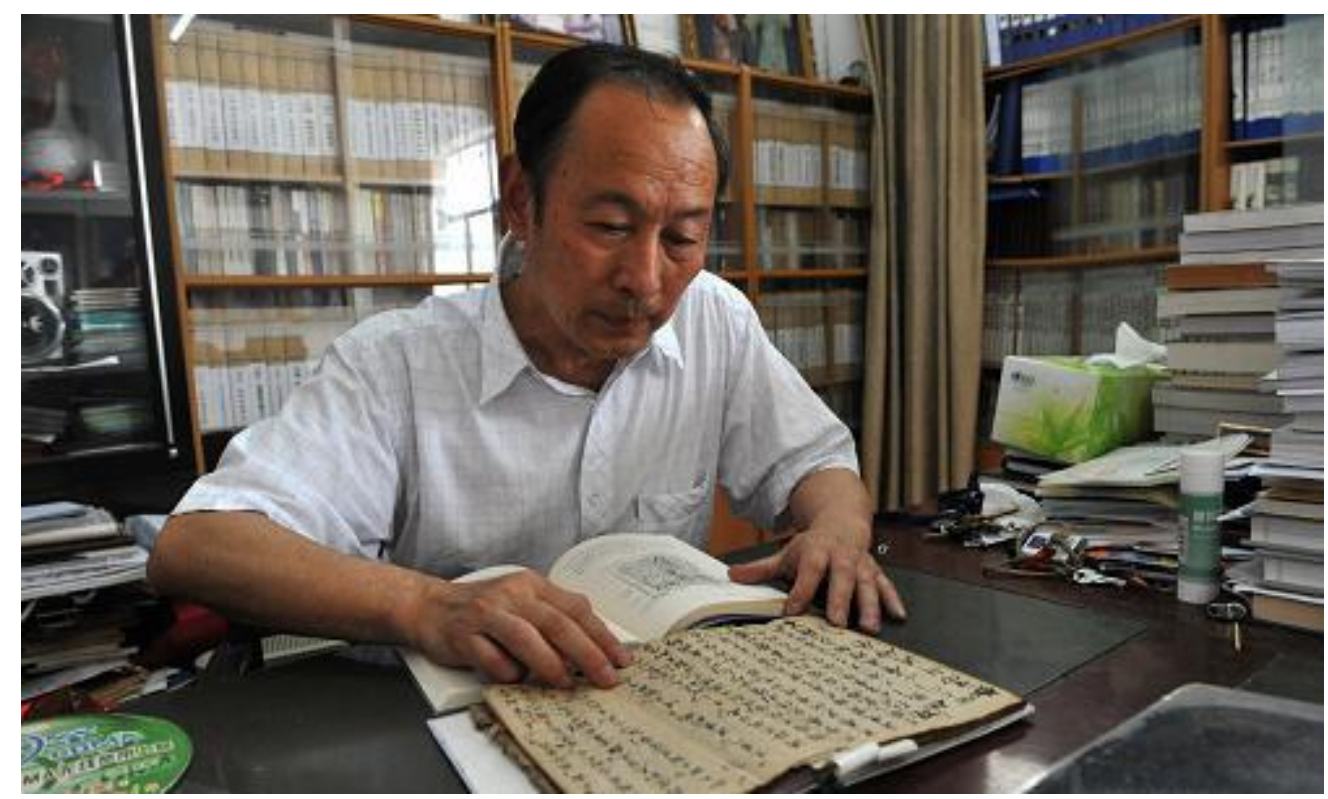

刘春江, 男, 1943 年 10 月出生于江西省鄱阳县鄱阳镇, 初中文化, 副研究馆员, 中共党 员, 九江市第十一、十四届政协委员, 中国音乐家协会会员, 中国傩戏学研究会会员, 中国 
民族管弦乐协会会员，江西省音乐家协会会员，江西戏曲音乐学会会员，九江市人民政府非 物质文化遗产专家组专家, 九江学院教授, 九江学院庐山文化研究中心研究员, 湖口县戏剧 创作研究室主任。
采写时间: 2016 年 12 月 20 日
采写地点: 九江学院艺术学院
采 写: 梅佳琪, 丁奕, 余红梅, 胡小美
摄 录: 梅佳琪

梅佳琪（以下简称 “梅”）: 刘老师，您好。今天很有幸能跟您做一个采访。能跟我们介绍 一下您的个人经历和艺术经历吗?

刘春江 (以下简称 “刘”): 我 15 岁, 在湖口进了黄梅戏曲团, 专门研究黄梅戏曲。当时 是搞音乐的, 我就想这一辈子, 恐怕就是搞黄梅戏搞下去了。之后, 把我调到文化馆当馆长, 经常组织宣传群众文化。有一次, 我们下乡到一个叫文桥乡的地方, 在这个村里头, 听到正 在打锣鼓唱戏, 这我就从来没听过, 因为我搞的是黄梅戏。这时, 正好台上有个女演员在唱, 我就问台下老艺人: “这是什么戏呀? 唱的这个是什么呀? ”老人说: “这是高腔戏, 台上唱 的是《白兔记》, 李三娘正在唱。” 我心里就在想, 还有这个戏呀? 因为我没接触过, 回来以 后, 我就查书, 就是周贻白先生写的《中国戏曲发展史纲要》。那个序言上就讲, 1956 年, 于 湖口都昌发现青阳腔。哎吆, 不得了, 这是青阳腔。因为青阳腔已经是 300 年没有音信了, 接着我就去查资料了, 资料越查越多。在国内外, 对青阳腔的研究早就已经断了, 正好我参 加了几次国际学术研讨会, 就是戏曲目连戏, 我就跟日本一些专家接触多一点, 跟我们本国 的专家接触不多，根据他们的建议说，青阳腔值得研究，因为青阳腔一时断了，没有人研究。 我就装在心里了, 之后, 找了很多杰出的 (文献、资料)。我请了 7 位老艺人拿个录音机, 把 他们带到偏僻 (安静) 一点的地方录音, 把这些东西录下来, 这些录音是绝对的珍贵嘛, 只 有三盘。我还没记, 有的听得懂, 有的听不懂, 有的一句话, 你要听一两天才听得清楚, 才 记得下来。好多人说唱错了, 其实没有错, 它中间有变调。你说她嗓子不好, 唱错了, 其实 不是, 它中间可以转调, 这个非常难。你一转调, 你按照前面的写下去, 你要把后面的音也 转调才行, 是吧! 这些东西非常关键, 我几十年解决了这些事, 包括搜集资料, 跟着学习。

梅: 请跟我们说说您在青阳腔方面的研究。

刘：青阳腔是明代，嘉靖年间，恐怕还早一点，是汤显祖讲的嘉靖年间。现在真正有文 学记载的, 就是汤显祖讲的。所以, 正阳腔自嘉靖, 七阳腔没有了, 变为了洛平腔, 变为了 青阳腔, 变为了徽州腔, 其他都没有了。我们只有这个根据了, 没有其他根据了。所以, 我 们这接受了这个以后, 我就一直都是根据这个思路, 去研究去搜集资料。《中国大百科全书》 戏曲曲艺卷 290 页, 专门介绍青阳腔, 就提到了湖口青阳腔, 而且配一张照片, 就是湖口青 阳腔老艺人的一张张飞的照片, 你说这个多清楚, 这个都有国家定论的啦, 进入了大百科全 书。所以, 我就按照这个思路去加强研究, 而且研究这些东西的时候, 接触的东西多了, 发 现它跟民俗、宗教、民间音乐都是紧密地结合在一起。我到过很多地方, 跑过大半个中国都 是去找这个青阳腔的发展, 它的发展史, 一直到现在我们那里还有, 农民剧团, 包括国家级 的传承人，省一批的传承人，都送过去了，帮他们申报，现在我手上就有很多录像，观点、 唱腔的录音我都有, 所以我出了 3 本著作, 一本是与我们九江学院合作写的《湖口青阳腔》, 申报了国家级的课题。再一个, 就是《<缘与梦>一一追随青阳腔 30 年》, 这是我自己写的。 第三部就是我把音乐搞出来了, 青阳腔 496 首, 包括音乐、锣鼓曲牌, 全部都有分类出来, 在北京通过广播影视出版社出版的。中国青阳腔出了 4 部书，我就占了 3 部。

30 多年了，我专门研究这个 (青阳腔)，而且现在收集的资料也非常多，剧目我收了 30 多本戏, 另外, 我通过日本东京大学的教授都复印过来了, 还有, 保存在丹麦、奥地利、维 也纳图使馆、皇家图书馆, 我就告诉你, 都复制过来了。所以, 这些太珍贵了, 太珍贵了。这 么多年来, 移居海外, 也不仅光是把东西搞回来, 你还付出心血去研究, 这是非常不容易的。 
去年, 我带了 9 个同志到韩国去演出青阳腔, 参加了韩国阿里郎艺术节, 我们这个小县的艺 术团体可以到国外去演出, 真是非常不容易的, 是民族音乐走向世界。所以说, 我们不仅研 究青阳腔, 要去保护、要传承, 现在为什么有些传不下去呢, 我们中国的戏剧剧种, 从解放 初有 300 个, 现在几乎几天有一个剧种绝了, 让我非常心痛。就拿青阳腔来说吧, 国家级的 传承人两个, 湖口有一个, 安徽青阳县有一个, 安徽青阳县的去世了, 就剩在我们江西九江 这一位。剩下一位, 省一级的传承人我也只保留一个, 只保留有一个, 但是现在安徽申报没 有批准, 你说这样的怎么去传承? 还有一个, 传承的主体是传承人, 保护的主体是政府, 你 政府要保护, 不仅是保护资料, 你拿着资料放在仓库里就不行, 关键是要保护活的传承人。 现在非物质文化遗产保护做得最好的国家是日本、韩国、意大利, 这几个国家做得非常好, 保护的资料非常多。我们自己，现在关键是传承的主体，传承人要发挥大的作用。

梅: 在您研究青阳腔的过程当中, 有没有什么人或事让您影响深刻的呢?

刘: 太多了, 最深的应该是老艺人的传承。我家在城市里, 很少下乡。接触了青阳腔以 后你不跟老艺人打成一片, 不接触老艺人就不行。第一次我开青阳腔老艺人座谈会, 问他们 有资料不? 他们说没有, 都给文化大革命烧了, 什么都没有。很难过呀! 但是, 还是要多给 老艺人交流, 你是后辈要尊重前辈, 所以这些老艺人跟我在一起非常好, 他们还请我到家里 吃饭。所以这些老艺人你要尊重他, 才能从他口里、手上拿到一点东西, 如果你不尊重他, 他是不会给的。而且这些老艺人收藏得非常精, 接触了以后我才晓得。他们湖口把青阳腔叫 “种子”，有一个全国青年作家写的一个文章，名字就叫 “种子”。专门写我的，他在这上面 就写我跟这些老人怎么接触的事, 他们把这些看做是种子, 要让他们拿出来是要他们的命呀! 这是一个种子。

这些文化大革命没有烧掉的、没被抄家的，说是不拿出来要怎么怎么的，大部分都交出 来了, 但仍有一部分老人爱这些种子跟爱自己命一样的, 用塑料布包上以后埋在土里, 有的 用瓦罐装着埋在土里, 有用塑料布包上藏在房顶墙角的。现在目前, 我手中最早的是光绪九 年的, 还有光绪十六年的、明国十七年的都是收藏品, 而且我收藏到一本锣鼓曲牌, 还有唢 呐曲牌、笛子曲牌, 手抄的老年人比我年纪还大, 这些东西太珍贵了。所以我领奖的时候说, 代表这些老年人, 结果他们去世了。这些老年人去世, 家里面的中堂是我给他写的, 花圈是 我送的, 送上山也是我一起送的。

梅: 您就是他们的亲人。

刘：恩，所以我把这些东西作为是我的生命。曾经有人写我一篇文章这么写过，说 “刘 老师的血管流的是青阳腔的血, 心脏跳的是青阳腔的节奏节拍!”我自己也把生命融到青阳腔 里, 所以, 我这一直做到现在, 谁再说对青阳腔不尊重, 对非物质遗产不重视, 就太说不过 去了。你到我家去看看, 我所有的剧目都是一个盒子、一个盒子的装起来, 所有论文和搜来 的一篇篇的资料都是放盒子里。家里房子不大, 但是够放下它们。这次安徽芜湖要申报目连 戏, 因为我参加过几次国内外的学术讨会, 有很多论文。我说, 只要你们做, 你们就拿着去, 拿去以后你记得还给我就行了, 至于你怎么去复制都是可以的。青阳腔, 我拍的老艺人的几 个戏, 有一个他们要, 拿着去复制以后还给我, 这些就是传承呀! 是保护意识的传承呀。有 些人就问, 刘老师东西你就送人了? 我就说, 你别搞错了, 多一个诚恳的人来跟我学, 就多 一个人去保护它呀! 这有什么不行, 这又不是我生产出来的东西, 这是国家级的遗产。做了 这件事, 我心里非常舒服, 是吧! 包括我孩子说, 你怎么把这东西随随便便就送人? 我就说, 我这留着干嘛呀! 我这不是送人, 是让他们普及这个知识, 让更多人懂得保护传承的价值。

梅: 您对青阳腔的付出让我们很感动, 非常感谢刘教授接受我们的采访!

\section{结语}

根据文化部《关于全面推进开展国家级非物质文化遗产代表性传承人抢救性记录工作的 通知》 (文非遗函 [2015]318号) 的要求, 全国已启动高龄国家级非物质文化遗产代表性传承 人抢救性保护工程。以非物质文化遗产传承人口述史访谈这种方式, 能更好地把握文化遗产 
研究的脉络, 从而为遗产学、艺术学的发展提供新思路。

\section{致谢}

本文为2016年江西省社会科学 “十三五” 规划基金青年项目 “赣北传统音乐代表性传承 人口述史研究” (项目编号：16YS35）的阶段性成果；2015年江西省艺术科学规划项目 “江 西音乐类非物质文化遗产传承人口述史研究”（项目编号：YG2015175）的阶段性成 果; 获江西省文化艺术科学重点研究基地 “九江学院民族民间文化艺术研究基地” 支持。

\section{References}

[1]Ary,D.,Jacobs,L.C.,and Razavieh.A Introduction to Research in Education.Australia:Wadsworth,2002.

[2]Donald A.Ritchie,Doing Oral History.Viney,L.L.\&Bous-field,L.1991.

[3]Anderson,Kathryn, and Dana C.Jack. "Learing to Listen:Interview Techniques and Analyses",In Women's Words:The Femi-nist Practice of Oral History,edited by Sherna Berg Gluck,and Daphne Patai,New York,and London:Rutledge,1991 